\title{
Micellization and Thermodynamic Properties of Cationic Surfactant Cetyltrimethylammonium Bromide in non-Aqueous Mixture of Lauric Acid
}

\author{
Zaheer Khan ${ }^{1, *}$, Maqsood Ahmad Malik ${ }^{1}$, Shaeel Ahmed AL-Thabaiti ${ }^{l}$, Abdulmohsen Alshehri, \\ Firdosa Nabi ${ }^{2}$ \\ ${ }^{1}$ Chemistry Department, Faculty of Science, King Abdulaziz University, P.O. Box 80203, Jeddah, \\ 21589, Saudi Arabia \\ ${ }^{2}$ Department of Chemistry, University of Malaya, Kuala Lumpur 50603, Malaysia \\ *E-mail: drkhanchem@yahoo.co.in
}

doi: $10.20964 / 2017.05 .53$

Received: 19 December 2016 / Accepted: 16 March 2017 / Published: 12 April 2017

In this work, the multi technique approach has been utilized to study the intermolecular interactions in lauric acid with the cationic surfactant cetyltrimethylammonium bromide in non aqueous media. The pseudo-phase separation model was used for the calculation of various thermodynamic parameters like standard free energy, $\Delta G^{o}{ }_{m i c}$, enthalpy, $\Delta H^{o}$ mic , and entropy, $\Delta S^{o}{ }_{\text {mic }}$, of micelle formation. The interfacial properties (the maximum surface excess at the air/solvent interface, $\Gamma_{\max }$, the minimum area per surfactant molecule at air/solvent interface, $A_{\min }$ ) of mixed system were calculated by using the Gibbs adsorption isotherm. The density data were applied to calculate the apparent molar volumes at infinite dilution, $V_{\phi}^{o}$, apparent molar volumes at the critical micelle concentration, $V_{\phi}^{c m c}$, and apparent molar volumes upon micellization, $\Delta V_{\phi}^{m}$, at 298.15, 303.15, 308.15 and $313.15 \mathrm{~K}$. The $1 \mathrm{H}$ NMR analysis suggested the intermolecular interaction especially in the hydrophilic head and interface region of CTAB with regard to shifting of proton signals.

Keywords: Micellization; Hydrophobic; Lauric acid; CTAB; Thermodynamics

\section{$\underline{\text { FULL TEXT }}$}

(C) 2017 The Authors. Published by ESG (www.electrochemsci.org). This article is an open access article distributed under the terms and conditions of the Creative Commons Attribution license (http://creativecommons.org/licenses/by/4.0/). 